\title{
Correction to: Population pharmacokinetics-pharmacodynamics of fondaparinux in dialysis-dependent chronic kidney disease patients undergoing chronic renal replacement therapy
}

\author{
Danica Michaličková1 ${ }^{10}$. Jan Miroslav Hartinger ${ }^{1}$ - Zuzana Hladinová ${ }^{2}$. Vladimíra Bednářová ${ }^{2}$. \\ Barbora Szonowská $^{3}$ - Vladimír Polakovič ${ }^{3}$. Andreas Matthios ${ }^{1,4}$. Vladimír Tesař $\cdot$ Ondřej Slanař ${ }^{1} \cdot$ Elke H. J. Krekels $^{5}$
}

Published online: 16 September 2021

(c) Springer-Verlag GmbH Germany, part of Springer Nature 2021

Correction to: European Journal of Clinical Pharmacology https://doi.org/10.1007/s00228-021-03201-1

In Table 4, there were mistakes in citations:

instead of Turpie (2004) [20], Ho et al. (2013) [20] should stand;

instead of European Medicines Agency (2021) [5], Speeckaert et al. (2013) [5] should stand;

instead of Speeckaert et al. (2013) [6], Mahieu et al. (2013) [6] should stand;

instead of Ho et al. (2013) [21], Sombolos et al. (2008) [21] should stand;

instead of Hartinger et al. (2020) [8], Kalicki et al. (2007)

[8] should stand.

Publisher's Note Springer Nature remains neutral with regard to jurisdictional claims in published maps and institutional affiliations.

The original article can be found online at https://doi.org/10.1007/ s00228-021-03201-1.

Danica Michaličková

marrtta@gmail.com

1 Institute of Pharmacology, First Faculty of Medicine \&,

General University Hospital, Charles University, Prague,

Czech Republic

2 Department of Nephrology, First Faculty of Medicine, Charles University and General University Hospital, Prague, Czech Republic

3 Internal Department of Strahov, General University Hospital, Prague, Czech Republic

4 Department of Biophysics and Physical Chemistry, Faculty of Pharmacy, Charles University, Hradec Králové, Czech Republic

5 Division of Systems Biomedicine and Pharmacology, Leiden Academic Centre for Drug Research, Leiden University, Leiden, Netherlands 